\title{
Economic Growth, Development, and Innovation: The Transformation Towards a Knowledge-Based Bioeconomy
}

Andreas Pyka and Klaus Prettner

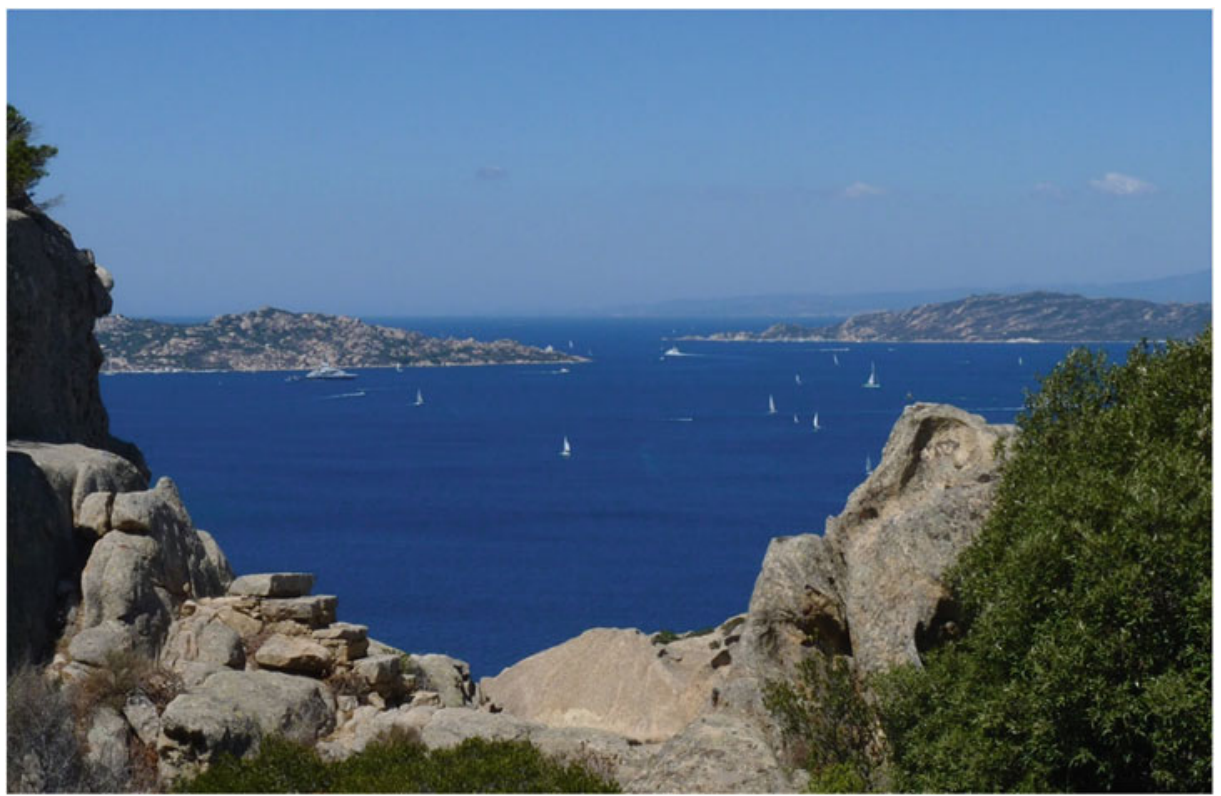

(C) Jürgen Jarosch

A. Pyka $(\bowtie)$

Institute of Economics: Innovation Economics, University of Hohenheim, Stuttgart, Germany

e-mail: a.pyka@uni-hohenheim.de

\section{K. Prettner}

Institute of Economics: Growth and Distribution, University of Hohenheim, Stuttgart, Germany e-mail: klaus.prettner@uni-hohenheim.de 


\section{Abstract}

To improve sustainability, the global economic system has to undergo severe transformation processes. This chapter deals with the possibility of an innovation-triggered transformation towards a knowledge-based bioeconomy, which is supposed to overcome the current lock-in into a fossil fuel-based $\mathrm{CO}_{2}$-intensive production. To do this, a neo-Schumpeterian view is applied that highlights the complex interplay in knowledge generation and knowledge diffusion processes between firms, consumers, and government institutions. By applying the neo-Schumpeterian approach, it becomes obvious that innovation and economic growth are part of the solution and not part of the sustainability problem. The shift from quantitative growth to qualitative development makes the difference and affects all agents and institutions in an economic system, which needs to be designed as a dedicated innovation system supporting the transformation towards a knowledge-based bioeconomy.

\section{Keywords}

Knowledge-based bioeconomy - Neo-Schumpeterian approach • Economic growth - Development - Innovation system - Economics of change

\section{Learning Objectives}

After studying this chapter, you should:

- Understand the technological, political, and social shifts that are necessary to achieve a transformation to a sustainable bio-based economy.

- Be able to assess the differences between the two approaches: (1) conservation of resources by growth abstinence and (2) decoupling of growth and exploitation of resources.

- Understand the foundations of the neo-Schumpeterian framework in the analysis of radical innovations.

- Be able to thoroughly discuss the challenges, opportunities, and consequences of innovations such as the "sharing economy," "biofuels," and "digitalization" in the transformation towards a knowledge-based bioeconomy.

\subsection{Introduction}

The sustainability of modern economic growth, as it developed in the todays Western industrialized economies from the beginning of the industrial revolution at the end of the eighteenth century, has been questioned at the latest since 1972 when the book The Limits to Growth was published by the Club of Rome (Meadows et al. 1972). After more than 200 years of industrial production, large parts of the world population are richer than ever before. However, industrial production in its current form is also closely linked with the exploitation of natural resources and the strong accumulation of greenhouse gases in the atmosphere, endangering human survival. In economics two fundamentally different solution strategies are discussed as a reaction on man-made climate change and irreversible environmental damages: (1) conservation of resources by growth abstinence and (2) decoupling of growth and exploitation of resources. In this chapter, we show that the first perspective with its emphasis on the efficiency of price competition is not suited to conceive a transformation of the production system towards a knowledge-based bioeconomy. Only the emphasis of the superiority of innovation competition, inherent to the second perspective, allows 
for the inclusion of the required transformative perspective.

The supporters of the first approach (e.g., Blewitt and Cunningham 2014; Kallis et al. 2014), summarized under the headings of abstinence and downscaling, claim a renunciation of our lifestyles based on consumption and increasing deployment of resources. This is considered the only way to enable a sustainable and environmentfriendly lifestyle and form of economic activity. At first sight, it might look surprising that these growth-hostile approaches are strictly in line with the thinking put forward in mainstream neoclassical growth theories. This follows from the fact that the standard neoclassical approach relies on the assumption of stable economic structures and an understanding of economic growth as a continuous increase in the quantity of the goods that are produced. Figure 11.1 depicts the impressive growth performance of the German economy, where-in particular in the period of the so-called Wirtschaftswunder after 1945-income per head skyrocketed: at the beginning of the twenty-first century, per capita GDP is approximately four times higher than three generations earlier. But does this mean that German consumers today have four Volkswagen Beatles in their garages? Obviously not! Today we have completely different goods and services in our consumption baskets, we acquire different competences in universities, we work in different jobs, etc. Restricting economic growth analysis to a quantitative dimension only dismisses these most important qualitative dimensions. Such an analysis can only serve for a very short-term observation.

The alternative approach of neo-Schumpeterian economics (e.g., Hanusch and Pyka 2007) challenges this quantitative orientation and instead emphasizes the importance of qualitative aspects, which make fundamental changes of economic structures over longer periods visible. Without the consideration of the qualitative levels of economic growth, the quantitative figures cannot tell much about the massive technological and socioeconomic developments. The neo-Schumpeterian approach highlights that innovations, market forces, structural change, and urban ways of life are both part of the problem and part of the solution to the sustainability problem. Innovation-triggered development generates both quantitative, i.e., income-increasing growth, and qualitative, i.e., structure-changing development. Only the creative solutions characteristic for capitalisticorganized economies will enable to reform our future economy in the sense of sustainability, thereby supporting the UN's sustainability goals and simultaneously ensuring growth and development (Mazzucato and Perez 2015).

The central role of innovation in neo-Schumpeterian economics highlights that abstinence in the sense of economic downscaling is neither the first nor the only solution. This does not mean that all ideas of the proponents of the camp are rejected: in perfect accordance, certain
Fig. 11.1 GDP per capita in Germany (Maddison 1995)

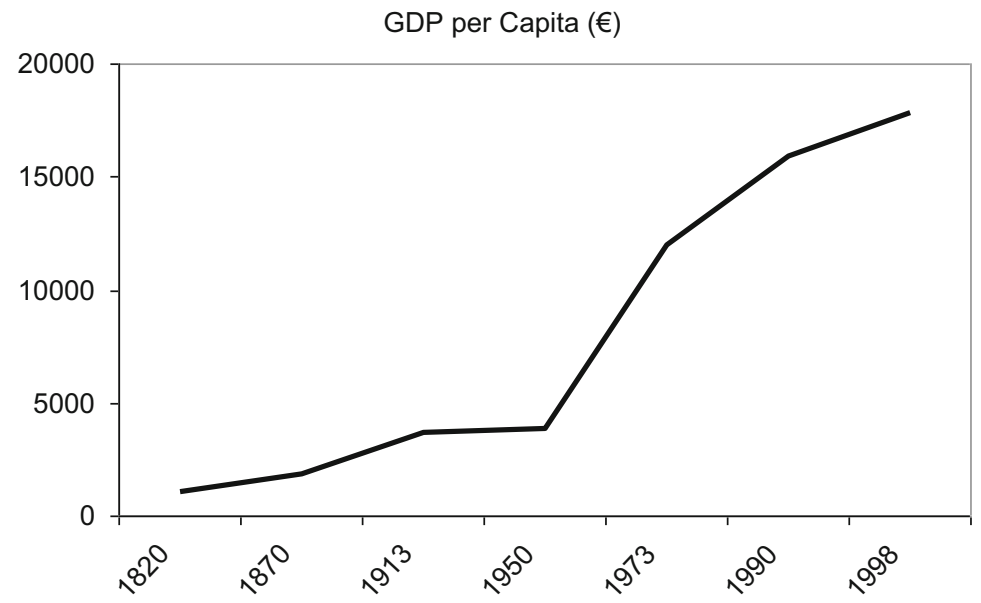


past patterns like the high energy intensity of production because of too low oil prices not covering the total environmental costs or so-called planned obsolescence in consumption require urgent adjustments. Especially concepts resulting in a more intensive use of goods and therefore contributing to the economization of resources like the sharing economy or displacing physical goods by digital goods are promising. The same applies for closed-loop material cycles, recycling systems, and intelligent waste avoidance and treatment. These concepts are perfectly applicable to foster learning and behavioral changes on the supply and the demand side. The core idea of neo-Schumpeterian economics, however, is the supply of and demand for new technological solutions within a comprehensive economic transformation process (Geels 2002), i.e., different goods and services are produced and demanded in different, namely, sustainable ways. Exploring and exploiting the technological possibilities of the bioeconomy not only creates new investment opportunities but is also the condition sine qua non for the required socioeconomic and cultural changes. The consumers' acceptance of bio-based products and their demand are indispensable for a successful transformation. Innovations and changed consumer attitudes are complementary conditions for the creation of a sustainable production system.

Change can be either of an incremental type in terms of small improvements step-by-step along well-known technological trajectories, or it can be fundamental, leading to structural changes and the emergence of new and the disappearance of old industries. To simplify, we assume in this chapter that incremental technological changes are based on existing technological solutions, whereas radical technological changes question major existing production processes. They might lead to massive upheaval in the global production system in the sense of creative destruction (Schumpeter 1943). Because this chapter deals with the fundamental transformation of current production systems, radical technological innovations are in the spotlight which encompass the overcoming of the lock-in situation in fossil fuels (Unruh 2000) and the establishment of a knowledge-based bioeconomy (Pyka 2017; Pyka and Buchmann 2016). Without doubt this transformation process is radical, qualitative, and long term. It was already in Business Cycles, published in 1939, when Schumpeter revitalized Kondratieff's theory of long waves in order to explain such processes as regular processes in long-term economic development. His illustration of the discontinuous nature of economic development is famous: "Add successively as many mail coaches as you please, you will never get a railway thereby" (Schumpeter 1934, p. 64). So far, the literature highlights five long waves: The beginning industrialization around the year 1800 represented the first long wave and was fueled by the steam engine and by cotton processing. Then, starting around the year 1850, the widespread availability of steel and the diffusion of railways constituted a second long wave. Again, in the early twentieth century, this Kondratieff cycle was replaced by electricity and chemicals. In the postwar period, the third long wave gained momentum by mass production and the automobile as well as the petrochemical industries. Since then, manufacturing activities built on oil as a second fossil fuel apart from coal. From the 1980s, one refers to the fifth long wave, which is reflected in the fast and ubiquitous diffusion and application of information and communication technology. Now, at the beginning of the twenty-first century, another paradigmatic change is in the air, being characterized, however, by one major difference to previous situations of radical change: whereas previous cycles were driven by technological bottlenecks and their overcoming, in the twentyfirst century, we face the vital question of how to restore environmental sustainability of economic activities. The knowledge-based bioeconomy plays a key role in this transformation process which, of course, like previous radical changes, still is confronted by fundamental uncertainty (Knight 1921).

The literature provides many alternative terms for the massive change, shaking global production systems: Freeman (1991) and Dosi (1982) call them techno-economic paradigm changes; Sahal (1985) uses cartographic analogies and refers to technological guideposts that are pointing to technological avenues. All authors highlight the confrontation with profound changes economic systems are faced with over 
longer periods of time, which question all established production approaches. Not a single technology is responsible for this phenomenon but several complementary developments that include, apart from a package of mutually dependent technologies (e.g., combustion engine, petrochemistry, assembly line production), numerous infrastructural developments (e.g., road structure, filling station network), behavioral changes (e.g., suburbs and commuter flow, shopping malls outside the city centers), as well as institutional changes (e.g., spatial planning and commuter allowance, etc.). The old paradigm will not be replaced by the new one until all these elements interact.

The neo-Schumpeterian approach provides us with crucial hints on the process of the forthcoming change. For this purpose, we discuss in the following section how innovations are supported by the discovery and successful diffusion of new knowledge. Knowledge-based economies organize innovation systems composed of different actors which establish a creative environment for mutual learning and knowledge creation. No innovation would have ever been established if it had not attracted consumers' interest and if it had not been leveraged by their purchasing power. We will focus on these questions in Sect. 11.3. Knowledge-based societies consider new concepts in the sense of responsible innovation that are decisive in bringing an entire economy on a new sustainable path-shaping growth and development. Section 11.4 deals with the massive economic impacts originating from these technological and knowledge-driven changes. It requires, besides technological change, also institutional change in a coevolutionary fashion, if new sustainable technologies are to achieve the aspired transformation of the economic system.

\subsection{Innovation Systems and Knowledge}

Neo-Schumpeterian scholars (e.g., Dosi et al. 1988; Lundvall 1992, 1998; Nelson 1993) strongly emphasize the systemic character of innovation processes. So-called innovation systems are composed of different actors (companies, research institutions, political actors, consumers, etc.) and linkages between these actors (flows of goods, $R \& D$ cooperation, knowledge transfer relationships, user-producer relationships, etc.). These linkages are required to ensure mutual learning and common knowledge development to solve complex innovation challenges. Such systems are characterized by their dynamic and coevolutionary nature and are thus enormously complex, as both actors and their knowledge and linkages and interactions between actors may change over time.

Dosi (1982) takes this systemic conception as a starting point in defining technological paradigms as " $[\ldots]$ set of procedures, or a definition of the 'relevant' problems and of the specific knowledge related to their solution." Transferred to the knowledge-based bioeconomy, the core idea is substitution, i.e., replacing carbon-based materials and energy with bio-based materials and energy. This can only be achieved by applying a variety of technological processes in the entire breadth and depth of the value-added chain. In this process the exploration of economic complementarities in terms of crossfertilization of different knowledge fields matters. For example, to a large extent, digitalization allows for an extension of value chains by increasing the added value in new sustainable production sectors in a $\mathrm{CO}_{2}$-neutral way (e.g., by electric mobility based on renewables, by establishing so-called smart grids, etc.). The concept of technological paradigms also illustrates that a paradigm shift is not possible at any time. A window of opportunity will only occasionally be opened and allow for a paradigm shift when several interconnected technologies are established and the creation of conducive demand side and institutional conditions happens simultaneously. This, of course, also holds for the emergence of a new bioeconomic innovation system and requires a sound balance of the various actors and their activities. For this reason, we introduce the notion of a dedicated innovation system. 
The theory of industrial life cycles, which emphasizes the strong dynamics in the emergence and decline of industries, gives a first hint on the meaning of the development of a dedicated innovation system supporting the transformation towards a knowledge-based bioeconomy. Typically, industrial development is divided into four stages: (1) a development phase (new knowledge creates prerequisites for innovation), (2) an entrepreneurial and growth phase (many market entries of smaller innovative firms), (3) a saturation and consolidation phase (formation of industrial standards, mergers, and acquisitions as well as market exits), and (4) a downturn phase (oligopolistic competition in only less innovative industries) (e.g., Audretsch and Feldman 1996). Although the bioeconomy does not represent a well-defined industrial sector, understanding the theory of industrial life cycles is of crucial importance to govern the transformation process towards the knowledge-based bioeconomy. Without doubt, the bioeconomy has to be characterized as cross sectional. On the one hand, several new sectors will emerge, e.g., in the fields of bioplastic, waste management, or biorefineries. On the other hand, already existing sectors in the fields of vehicle construction, battery technology, pharmaceuticals, etc. will gain new momentum by the arrival of bioeconomic approaches. Therefore, we argue that new sectors will emerge by establishing bioeconomic technologies and development dynamics of some already existing industries will receive new impetus at the same time. Adjustments of old and development of new institutions (e.g., in Germany the Renewable Energy Act, the Greenhouse Gas Emissions Trading Law, etc.), adjustments of consumer habits, and the emergence of new educational opportunities in terms of coevolution will accompany these processes and establish the institutional, the industrial, and the consumer pillars of a dedicated innovation system.

The patterns and nature of new businesses in the bioeconomy are thus strongly influenced by national institutions and organizations (Casper et al. 1999; Whitley 1999). Institutions are defined as "a set of rules, formal or informal, that actors generally follow, whether for normative, cognitive, or material reasons." "Organizations are durable entities with formally recognized members, whose rules also contribute to the institutions of the political economy" (North 1990; Hall and Soskice 2001). In this interplay between organizations and institutions, the knowledge base of an economy is created by the education and research system and represents one of the most important prerequisites for the transformation towards a bioeconomic production system (Geels 2002). This automatically relates to a high level of uncertainty in particular concerning the required future competences. In this complex process, numerous individual knowledge fields are potentially relevant for the transformation and are already identified, e.g., synthetic chemistry, process engineering, genetic engineering, food technology, or informatics. It is decisive to understand the dynamics of these knowledge fields and the possibilities of their recombination with other knowledge fields and adequate actors in order to create an innovation system. In many cases, linkages of different knowledge fields (cross-fertilization) are responsible for the emergence of extensive technological opportunities: for instance, a complete new industry, bioinformatics, has been initiated by the fusion of two so far unrelated knowledge fields, database technology and molecular biology. Because linking different knowledge fields is highly uncertain, private actors might not start and governmental innovation policies matter. Knowledge about future potentials, therefore, is essential for supporting research and innovation policies: the analysis of knowledge and network dynamics allows for the identification of development trajectories showing sectors requiring public attention and support concerning research and development in order to close existing knowledge gaps and build bridges between various knowledge domains (Burt 2004; Zaheer and Bell 2005).

\subsection{Innovation in Knowledge- Based Societies}

It has already been mentioned that also consumer knowledge plays an important role for the 
development and establishment of sustainable consumption patterns in a knowledge-based bioeconomy (Geels 2002). Therefore, the analysis of the transformation process has to include the interaction of technological development, demand, and acceptance of innovative solutions as well as sociological variables. The latter include education, age, income, and gender. All are important explanatory factors determining attention and readiness to deal with bioeconomic issues. A bioeconomic innovation will only be successful when consumers accept it. The direction of the transformation process is, comparable to the importance of the policy realm, determined by consumers, i.e., an important question has to address consumers' openness to the bioeconomy and its products.

Finally, (real and virtual) social networks matter for the establishment of new consumption patterns. They can contribute significantly to a diffusion of consumers' behavioral patterns and values (Robertson et al. 1996; Valente 1996; Nyblom et al. 2003; Deffuant et al. 2005). Recent studies show that attitudes are substantial for the development of social relationships and that, in turn, social relationships considerably influence behavior and attitudes. In the field of renewable energies, for example, the initiative of municipal utilities' customers has led in many cases to a "green" orientation of regional power supply. In some cases, citizens' networks finally transformed to investment companies that are engaged in wind farms.

Critical issues are to be dealt with in democratic processes in order to be widely accepted. Not everything that is technically possible is also socially desirable. In the field of the bioeconomy, this may, for instance, include the use of genetically modified organisms in agriculture. In fact, these organisms promise efficiency advantages with regard to the consumption of land and water, etc., but their long-term health and environmental risks cannot be completely (as with any new technology) anticipated. Accordingly, technological developments require consumers' acceptance and thus depend on the level of education in an economy. This raises the question of a society's openness towards innovations that are fundamentally associated with uncertainty. The concept of responsible innovation summarizes the future-oriented organization of development and is currently discussed with a high priority by European policy makers and institutions. A comprehensive working definition has been developed by Von Schomberg (2011). He describes responsible innovation as "a transparent, interactive process by which societal actors and innovators become mutually responsive to each other with a view to the (ethical) acceptability, sustainability and societal desirability of the innovation process and its marketable products (in order to allow a proper embedding of scientific and technological advances in our society)." This means that innovations are not exclusively evaluated by their economic efficiency, but different aspects (e.g., consumer protection or ecological aspects; see Schlaile et al. 2017) also matter and are to be evaluated. Discussions on biofuels ("fuel vs. food") show that both a pure economic and a one-dimensional ethical perspective are not sufficient. The quality of these discussions depends on the discussants' mutual understanding which in turn depends on the participants' level of knowledge.

Modern plant breeding and production of seeds are bioeconomy fields of innovation in which issues of responsibility are discussed frequently and controversially. German consumers are skeptical about interference with the genome of food crops, but individual points of criticism remain unclear. New breeding techniques introduced, e.g., genome editing, enable scientists to selectively modify DNA strands of crop plants. These techniques are considered innovative as they may allow breeding of potentially efficient plants in fast and cheap ways. Species developed this way hardly differ from those of conventional breeding. The Central Advisory Committee for Biological Safety does not classify these techniques as genetic engineering, especially because no new combinations of genetic material are made. As the Genetic Engineering Act does not explicitly address these techniques, legal clarification is still necessary as to whether these techniques are classified as genetic engineering at all. Dissemination 
potential and acceptance are influenced by this result. Here again, the necessity to include education and information policies becomes evident to support the transformation towards a knowledge-based bioeconomy.

The concept of social innovation (e.g., Hanusch and Pyka 2013) emphasizes the importance of active citizenship in innovation. Thus, according to the understanding of the European Commission, this term includes innovations that are social, both in relation to their objective and their instruments. In particular, this includes innovations referring to the development and the application of new ideas (for products, services, and models), covering at the same time social demand and creating new social relationships or collaborations. The whole society should benefit and contribute to generate new impetus for improvement. Social innovations can make a major contribution to rural development and promote economic resilience in these regions by strengthening cooperative behavior. Rural cooperatives (e.g., regional producer and marketing associations, winegrowers' cooperatives, tourism associations, etc.) can help to develop regional competitiveness considering ecological and social aspects. As a consequence, within the framework of a bioeconomy, rural regions that are notably affected by the already imminent demographic change and subsequent depopulation receive new opportunities for economic development.

\subsection{The Economics of Change}

The sections above illustrate that a transformation of the prevailing economic system towards a bioeconomy is an extremely complex process. Various different actors participating in different roles are contributing different pieces of knowledge. In this process, innovative adjustments in already existing industries as well as the emergence of new and the disappearance of mature industries can be observed simultaneously. In addition to the substitutive relations of new bio-based industries to traditional oil-based industries, there are numerous essential complementary relations giving further momentum for the transformation process. First and foremost, there are the possibilities and application fields of digitalization. Digitalization allows to replace many oil-based products and energyintensive services simply by bits and bytes. Simultaneously, digitalization offers a wide range of opportunities by coordinating decentralized and very detailed bioeconomic technologies and processes such as energy production and distribution. This affects the composition of individual sectors where a coexistence of large diversified companies and small highspecialized technology companies is a likely solution. Finally, digitalization also offers consumer platforms to efficiently organize "sharing economy" approaches. Finally, successful knowledge generation and diffusion of relevant bioeconomic knowledge depends on dynamic innovation networks (Pyka 2002) in which different actors jointly share and create new knowledge. The consumers, represented, for example, by consumer associations or politics, will play a key role in these innovation networks and will help to establish networks in early stages of technology development.

In a knowledge-based bioeconomy, investment and economic growth still represent a crucial element for employment, international competitiveness, and income generation. The bioeconomy can make important contributions to accelerate investments by providing new investment opportunities generated by fundamental innovations and thereby bringing currently available large quantities of liquidity to a productive use. This, in turn, accelerates the technological paradigm shift (Pérez 2010).

The time path of the transformation process represents another critical component and has been explored only partially so far. On the one hand, it is high time to reduce carbon-based production methods. On the other hand, there will be frictions in the transformation process being caused, for example, by a lack of specialists and required competences. In this context, the so-called sailing ship effects (Howells 2002), frequently observed with radical innovations, could be made of good use. In the 
middle of the nineteenth century, when the existence of the established sailing ship technology was threatened by the arrival of new steam ships, shipbuilders-not having changed their technologies for many decades, if not centuries-began to innovate again. Due to the threat of innovative technologies, adjustment reactions in predecessor technologies can be observed with the aim to prevent the ancient technologies to be quickly replaced. Such adjustment reactions are, for example, fuel-efficient combustion engines and hybrid technologies as a reaction to the emergence of electric vehicles. These adjustments are advantageous since they pursue the same environmental objectives (e.g., inner-city fine dust and noise reduction, etc.) and thus provide more time to develop new technologies. Accordingly, the transformation process will for longer periods of time feature a coexistence of traditional and bio-based industries. Furthermore, it will be important to concurrently steer the relevant innovation processes in traditional technologies. This coexistence further increases complexity. At the same time, innovation policy is given room for maneuver and yet insufficiently developed technologies are prevented from being introduced prematurely which might cause promising approaches to fail.

Distributional effects of the transformation process are important for social acceptance. A bio-based economy on an industrial scale will largely represent a knowledge-based economy. Consequently, additional demand for highskilled workers arises whereas opportunities for low-skilled workers decrease. This means a potential loss of jobs for less skilled workers in traditional industrial production. But apart from that, there will be demand for different goods and services whose compensation potential with regard to added value and employment is still unclear. Moreover, it remains open to what extent companies are prepared for this transformation into the bioeconomy. Transformation processes will lead to a devaluation of competences so far responsible for economic success. How do established companies deal with the so-called not-invented-here syndrome, overcome operational blindness, and shape transformation processes actively in order to obtain added value at their established locations?

From this follows that distributional effects have an important regional dimension: does the bioeconomy strengthen divergence processes between regions or does it help to achieve more convergence? The approach of creating networks in the sense of the so-called smart specialization principle (Foray et al. 2009), connecting regional strengths along value-added chains in the best possible way, is promising but only sparsely implemented so far. Thus, in general, polarization tendencies leading to economic as well as political and cultural concentration of power and resulting in strong center-periphery structures can be avoided. But it still remains unclear, how strong and operational meaningful politically induced networks are in comparison to self-organized networks and how policy might exert influence. First findings indicate signs of a potential disintegration of the networks when political support is withdrawn (Green et al. 2013).

Transformation towards a knowledge-based bioeconomic production system is supposed to terminate the existing negative relations between economic growth and environmental pollution, use of resources, climate change, and energy consumption and to promote a sustainable economy. The following questions are closely linked to the basic uncertainty of innovation and cannot be answered ex ante: "which contributions are to be made by individual sectors?," "what complex feedbacks for national and international competitiveness are to be expected?," and "do the so-called rebound effects possibly reduce or even overcompensate the positive effects of the transformation?" Institutional rules, such as a self-commitment of oil-producing countries to reduce their outputs due to the declining demand caused by bioeconomics, are a way to reduce these uncertainties, at least partly. It remains necessary for the leading actors, companies, households, and policy makers to refrain from optimization approaches and profit maximization in this transformation process. The complexity and uncertainty of this process requires the awareness of all actors to experimental behavior 
(trial and error) which always also includes the possibility of failure.

\subsection{Conclusions}

Socioeconomic systems have been exposed to permanent transformation processes since the industrial revolution. While development processes so far have been driven "only" by resultoriented innovation processes, the character of the bioeconomic transformation process is clearly concretized by society and politics. In the past, mainly bottlenecks caused by scientific-technological restrictions were overcome by vast technological revolutions, shifting the socioeconomic system on new trajectories without giving direct instructions to the direction of the development process. At the beginning of the twenty-first century, however, the massive accumulation of greenhouse gases in the atmosphere since the beginning of the industrial revolution and the vulnerability of our present ecosystems reveal that global thresholds are almost surpassed. Thus, the level of freedom for future developments is restricted in order not to irreversibly damage natural conditions for human life and biodiversity. It is yet unclear whether this transformation process succeeds in the desired way and how it can be governed by political influence to achieve existential objectives of the global human society.

New technological developments alone are not enough to transform the socioeconomic system. In a first step, they only create the necessary potential for radical changes affecting the economy as a whole. Converging trajectories and synergies that may finally introduce the paradigm shift necessarily require a broad social consensus on a specific use of these technologies. This means an initiation of a direction of development which connects investment decisions, innovations, and the tackling of basic uncertainty by politics (Pérez 2013). The "green growth paradigm" based on bio-based technologies can be such a direction bringing together the potential of different technological developments and exploring their full potential. This requires political decisions supporting a new orientation of research and innovation activities, exploitation of new energy sources, improvements in productivity of natural resources, and new sustainable ways of living and producing (Pérez 2013). Moreover, in such a transformation process, catching-up economies have to be provided with new opportunities for economic development without overstretching global natural resources and environment. Thus, a political and social direction is essential for a successful transformation process (Mazzucato and Perez 2015).

Examples include the development of new products within emerging bioeconomic innovation systems. In this perspective, innovations require an interplay of actors along value-added chains which might lead to the development of new industries. In the past, for example, the provision of cheap electricity led to the spread of fridges and freezers in private households which brought innovations in the fields of frozen food and packaging. Similarly, the creation of a sharing economy may lead to new digital coordination platforms and the creation of sustainable designs by product manufacturers in the bioeconomy. Planned obsolescence, a phenomenon wasting resources and shortening product life cycles, would be eliminated this way, and new sectors, for example, in the field of repair and maintenance services are initiated. Important determinants shaping long-term development are networks and clusters. They help to reduce uncertainty and support self-reinforcing effects. Furthermore, social changes and changing lifestyles are both an expression and a driver of this transformation process (Mazzucato and Perez 2015).

Therefore, the role of governments is not only restricted to the correction of market failures. In fact, by ensuring investment safety and reducing risks and uncertainty, government instruments prepare the emergence and flourishing of new markets (Mowery et al. 2010). A crucial task for policies in the realm of innovation and entrepreneurship is the transition from invention to innovation, i.e., the expansion of bioeconomical 
activities in a market. Correspondingly, a growth path based on bioeconomics is more than a mere replacement of crude oil by renewable resources or renewable energies. It rather needs a dedicated innovation system creating synergies, knowledge transfer, and networks between manufacturers, suppliers, and consumers. It requires a comprehensive reorganization that includes the entire economy and renews production and consumption patterns in their present forms, which were shaped by previous transformation process within the oil-based paradigm.

The technological potential of a bioeconomy is a necessary but insufficient condition for this transformation process. It also requires democratic consensus on the broad development and wide application of this technological potential. This includes the exploration of new trajectories and the fusion of new and existing technological trajectories. Markets in which innovations are profitable do not arise on their own but rather need feedback loops between political decisions, corporate strategies, and consumer preferences.

\section{Review Questions}

- Discuss the likely social, economic, and environmental effects of the sharing economy. Put particular emphasis on the rebound effect that could emerge in this context due to the fact that the sharing economy makes the use of resources for individuals cheaper. How can policy makers counter this rebound effect?

- What does "creative destruction" mean? Provide two historical examples, where creative destruction has played a particularly important role.

- What are Kondratieff cycles and which are the inventions that are associated with them?

- Sketch the (1) mutually dependent technologies, (2) infrastructural developments, (3) behavioral changes, and (4) institutional changes that you expect to be necessary in the transformation towards a knowledge-based bioeconomy.

- What is a "dedicated innovation system" and how could it look like in case of the transformation towards a bio-based economy?
- Describe the term "responsible innovation" and discuss its meaning in the context of genome editing.

\section{References}

Audretsch D, Feldman MP (1996) Innovative clusters and the industry life cycle. Rev Ind Organ 11 (2):253-273

Blewitt J, Cunningham R (eds) (2014) The Post-Growth Project: how the end of economic growth could bring a fairer and happier society. Green House, e-prints, Aston University

Burt RS (2004) Structural holes and good ideas. Am J Sociol 110(2):349-399

Casper S, Lehrer M, Soskice D (1999) Can hightechnology industries prosper in Germany? Institutional frameworks and the evolution of the German software and biotechnology industries. Ind Innovat 6(1): 114-139. https://doi.org/10.1080/13662719900000002

Deffuant G, Huet S, Amblard F (2005) An individual-based model of innovation diffusion mixing social value and individual benefit. Am J Sociol 110(4):1041-1069

Dosi G (1982) Technological paradigms and technological trajectories: a suggested interpretation of the determinants and directions of technical change. Res Pol 11(3):147-162

Dosi G, Freeman C, Nelson R et al (eds) (1988) Technical change and economic theory. Pinter, London

Foray D, David PA, Hall B (2009) Smart specializationthe concept. Knowledge Economists Policy Brief. doi: https://doi.org/10.1016/j.pcad.2013.03.008

Freeman C (1991) Networks of innovators: a synthesis of research issues. Res Pol 20(5):499-514

Geels FW (2002) Technological transitions as evolutionary reconfiguration processes: a multi-level perspective and a case-study. Res Pol 31(8):1257-1274

Green L, Pyka A, Schön B (2013) A life-cycle based taxonomy of innovation networks - with focus on publicprivate collaboration. In: Gallouj F, Rubalcaba L, Windrum $\mathrm{P}$ (eds) Public-private innovation networks in services. Edward Elgar, Cheltenham, pp 113-138

Hall PA, Soskice D (2001) An introduction to varieties of capitalism. In: Hall PA, Soskice D (eds) Varieties of capitalism: the institutional foundations of comparative advantage. Oxford University Press, Oxford, pp 1-68

Hanusch H, Pyka A (2013) Social innovations in the perspective of comprehensive Neo-Schumpeterian economics. In: Ruiz Viñals C, Parra Rodríguez C (eds) Social innovation-new forms of organization in knowledgebased societies. Routledge, London, pp 29-43

Howells J (2002) The response of old technology incumbents to technological competition-does the sailing ship effect exist? J Manag Stud 39(7): 887-906

Kallis G, Kerschner C, Martinez-Alier J (2014) The economics of degrowth. Ecol Econ 84:172-180 
Knight FH (1921) Risk, uncertainty and profit. Hart, Schaffner \& Marx, Boston

Lundvall BA (1992) National innovation systems: towards a theory of innovation and interactive learning. Pinter, London

Lundvall BA (1998) Why study national systems and national styles of innovation? Technol Anal Strat Manag 10(4):403-422

Maddison A (1995) Monitoring the world economy 18201992. OECD, Paris

Mazzucato M, Perez C (2015) Innovation as growth policy. In: Fagerberg J, Laestadius S, Martin BR (eds) The triple challenge for Europe: economic development, climate change, and governance. Oxford University Press, Oxford, p 229

Meadows D, Randers J, Behrens WW (1972) The limits to growth. Universe Books, New York

Nelson RR (1993) National innovation systems: a comparative analysis. Oxford University Press, Oxford

North DC (1990) Institutions, institutional change and economic performance. Cambridge University Press, Cambridge, MA

Nyblom J, Borgatti S, Roslakka J et al (2003) Statistical analysis of network data-an application to diffusion of innovation. Soc Netw 25(2):175-195

Pérez C (2010) Technological revolutions and technoeconomic paradigms. Camb J Econ 34(1):185-202

Pérez C (2013) Financial bubbles, crises and the role of government in unleashing golden ages. In: Pyka A, Burghof HP (eds) Innovation and finance. Routledge, Milton Park, pp 11-25

Pyka A (2002) Innovation networks in economics-from the incentive-based to the knowledge-based approaches. Eur J Innovat Manag 5(3):152-163

Pyka A (2017) Die Bioökonomie unter dem Blickwinkel der Innovationsökonomie. In: Pietzsch J (ed) Bioökonomie für Einsteiger. Springer, Berlin
Pyka A, Buchmann T (2016) Die Transformation zur wissensbasierten Bioökonomie. In: Burr W, Stephan M (eds) Technologie, Strategie und Organisation. Springer, Berlin, pp 333-361

Robertson M, Swan J, Newell S (1996) The role of networks in the diffusion of technological innovation. J Manag Stud 33:333-360

Sahal D (1985) Technological guideposts and innovation avenues. Res Pol 14(2):61-82

Schlaile MP, Müller M, Schramm M et al (2017) Evolutionary economics, responsible innovation and demand: making a case for the role of consumers. Philos Manag 16:1-33

Schumpeter JA (1934) The theory of economic development. President and Fellows of Harvard College, Harvard

Schumpeter JA (1939) Business cycles. A theoretical, historical and statistical analysis of the capitalist process. McGraw-Hill, New York

Schumpeter JA (1943) Capitalism, socialism and democracy. Harper, New York

Unruh CG (2000) Understanding carbon lock-in. Energ Pol 28:817-830

Valente TW (1996) Social network thresholds in the diffusion of innovations. Soc Netw 18(1):69-89

Von Schomberg R (2011) Prospects for technology assessment in a framework of responsible research and innovation. In: Dusseldorp $\mathrm{M}$, Beecroft $\mathrm{R}$ (eds) Technikfolgen abschätzen lehren: Bildungspotenziale transdisziplinärer Methoden. Springer, Wiesbaden, pp 39-61

Whitley R (1999) Divergent capitalisms: the social structuring and change of business systems. Oxford University Press, Oxford

Zaheer A, Bell GG (2005) Benefiting from network position: firm capabilities, structural holes, and performance. Strat Manag J 26(9):809-825

Open Access This chapter is licensed under the terms of the Creative Commons Attribution 4.0 International License (http://creativecommons.org/licenses/by/4.0/), which permits use, sharing, adaptation, distribution and reproduction in any medium or format, as long as you give appropriate credit to the original author(s) and the source, provide a link to the Creative Commons license and indicate if changes were made.

The images or other third party material in this chapter are included in the chapter's Creative Commons license, unless indicated otherwise in a credit line to the material. If material is not included in the chapter's Creative Commons license and your intended use is not permitted by statutory regulation or exceeds the permitted use, you will need to obtain permission directly from the copyright holder. 